\title{
Association between cell-bound haemolysin and cell-detaching activity of Escherichia coli isolated from children
}

Correspondence

Beata M. Sobieszczańska

mapasobie@provider.pl

Received 6 April 2005

Accepted 23 October 2005

\author{
Beata M. Sobieszczańska, ${ }^{1}$ Jacek Osek, ${ }^{2}$ Romuald Gryko ${ }^{3}$ \\ and Magdalena Dobrowolska ${ }^{1}$ \\ 1Department of Microbiology, University of Medicine, 4 Chałubińskiego Street, 50-368 \\ Wrocław, Poland \\ ${ }^{2}$ Department of Hygiene of Food of Animal Origin, National Veterinary Research Institute, \\ 57 Partyzantów Street, 24-100 Puławy, Poland \\ ${ }^{3}$ Military Institute of Hygiene and Epidemiology, 2 Lubelska Street, 24-100 Puławy, Poland
}

\section{INTRODUCTION}

Cell-detaching Escherichia coli (CDEC) strains were isolated from children with diarrhoea for the first time by Gunzburg et al. (1993). In the reversible intestinal tie adult rabbit diarrhoea (RITARD) model, Elliott et al. (1998) demonstrated that CDEC strains were able to elicit diarrhoea; however, the studies of Marques et al. (1995) and Okeke et al. (2002) have not confirmed the association of these strains with diarrhoea in humans. Marques et al. (1995), Gomes et al. (1995) and Okeke et al. (2002) showed that the majority of CDEC were haemolytic on blood agar during $3 \mathrm{~h}$ of incubation and hybridized with the DNA probe specific for haemolysin $\alpha$ (HlyA) of E. coli. However, these results were not confirmed by Fábrega et al. (2002). Moreover, most CDEC isolates tested did not demonstrate the genes for pathogenic E. coli virulence factors, such as heat-labile or heat-stable enterotoxins, cytolethal distending toxin (CDT) or Shiga toxins (Stx1 or Stx2), but did show the presence of genes for cytotoxic necrotizing factor 1 (CNF1). However, according to Elliott et al. (1998), CNF1 had no influence on cell-detaching activity of $E$. coli.

Since most CDEC isolates studied are HlyA-positive, this haemolysin is considered to be the main factor responsible

Abbreviations: CDEC, cell-detaching E. coli; EAEC, enteroaggregative E. coli; EHEC, enterohaemorrhagic E. coli; EIEC, enteroinvasive E. coli; HlyA, haemolysin $\alpha$. for cell detachment in vitro (Marques et al., 1995). HlyA is the prototype of the family of calcium-dependent RTX cytolysins and is actively secreted into the medium in the exponential growth phase. However, HlyA is not stable in the external environment and its haemolytic activity decreases to undetectable levels during the stationary phase of growth (Bohach \& Snyder, 1985). E. coli produces several other haemolysins. Enterohaemolysin of enterohaemorrhagic E. coli (EHEC), designated Ehx or Hly $\mathrm{EHEC}_{\mathrm{EHE}}$ is very similar to HlyA with regard to its genetic organization and calcium ion dependency although it is cell-bound (Taneike et al., 2002). To our knowledge, the influence of this type of E. coli haemolysin, as well as contact haemolysins described among enteroinvasive (EIEC) (Sansonetti et al., 1986) and enteroaggregative (EAEC) (Haque et al., 1994) E. coli strains, on cell-detaching activity has not been studied.

The present study was undertaken to determine the influence of cell-free HlyA and cell-bound haemolysins on the cell-detaching activity in vitro of 27 randomly selected haemolytic E. coli isolates obtained from human stool specimens.

\section{METHODS}

Bacterial strains. Twenty-seven haemolytic E. coli isolates randomly selected from faeces of 27 children with a mean age of 18 months, 20 with diarrhoea (20 isolates) and seven without diarrhoea (seven isolates) were examined. E. coli $\mathrm{K} 12$ strain $\mathrm{C}_{600}$ and 
six non-haemolytic E. coli isolates obtained from stool specimens (strains 101-106) were included as negative controls. Two E. coli O26 enterohaemolysin-positive strains obtained from children with diarrhoea (strains 738/O26 and 740/O26) and two E. coli strains that were haemolytic on blood agar plates after $24 \mathrm{~h}$ of incubation (strains 81 and 147) were used as controls in the cell-detaching assay (Table 1).

Haemolysin assay. For detection of haemolytic activity, the E. coli isolates were grown on tryptose soy agar with $5 \%$ defibrinated sheep blood or $5 \%$ sheep erythrocytes washed in saline $(0.85 \%)$ with or without $10 \mathrm{mM} \mathrm{CaCl}$ or $10 \mathrm{mM}$ EDTA added. The blood agar plates were incubated at $37^{\circ} \mathrm{C}$ for 4 and $24 \mathrm{~h}$ and then examined for the presence of haemolysis zones around bacterial colonies (Beutin et al., 1989).

Production of extracellular HlyA and cell-bound haemolysins. The standardized red blood cell (RBC) suspension in PBS-CM

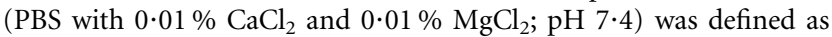
the quantity of washed RBCs that gave an absorbance of 1.0 at $550 \mathrm{~nm}$ after total lysis in $1 \mathrm{ml}$ distilled water. E. coli isolates were grown at $37^{\circ} \mathrm{C}$ for $4 \mathrm{~h}$ (exponential growth phase) or $24 \mathrm{~h}$ (stationary phase) in $2 \times$ yeast extract medium with $10 \mathrm{mM} \mathrm{CaCl} 2$. The culture supernatants were filter-sterilized $(0 \cdot 2-\mu \mathrm{m}$ pore-size $)$, mixed with an equal volume of $\mathrm{RBC}$ suspension and incubated at $37^{\circ} \mathrm{C}$ for $90 \mathrm{~min}$. The amount of released haemoglobin was determined spectrophotometrically at $550 \mathrm{~nm}$ (Bhakdi et al., 1986; Elliott et al., 1998). Bacterial cells of the same cultures were washed twice with PBS-CM and resuspended in the same buffer to a concentration of $3 \times 10^{8}$ cells $\mathrm{ml}^{-1}$ and haemolytic activity of the suspensions was determined as described above. The culture filtrates and the bacterial cells were also incubated at $37^{\circ} \mathrm{C}$ for $90 \mathrm{~min}$ without $\mathrm{RBCs}$ and then tested to determine the influence of the incubation period on haemolytic activity. Haemolytic activity was also measured in filtersterilized supernatants obtained from bacterial cell suspensions in PBS-CM incubated at $37^{\circ} \mathrm{C}$ for 90 min to determine whether cellfree haemolysin was released into the environment during that period. Haemolytic activity was expressed as the mean percentage of haemoglobin released in two independent assays in comparison to total lysis of RBCs in water.

Osmotic protection assay. Standardized RBC suspensions were prepared in PBS-CM containing one of the following substances: $30 \mathrm{mM}$ dextran 4, $30 \mathrm{mM}$ dextran $8,30 \mathrm{mM}$ sucrose (Bhakdi et al., $1986)$ or an alcoholic solution of cholesterol $\left(10 \mathrm{mg} \mathrm{ml}^{-1}\right)$ (Figueirĕdo et al., 2003). Haemolytic activity of the culture filtrates from exponential and stationary growth phases of the isolates and the corresponding bacterial cell suspensions were then determined as described above.

Influence of UV irradiation and heating on haemolytic activity. Exponential and stationary culture filtrates and bacterial cell suspensions were tested for haemolytic activity as described above after UV irradiation for $10 \mathrm{~min}$ and after heating at $56^{\circ} \mathrm{C}$ for 10 min (Jorgensen et al., 1976).

Cytolysin ClyA expression assay. The ability of E. coli isolates to express cytolysin ClyA was determined on $1 \%$ Columbia agar containing $5 \%$ horse RBCs washed with PBS as described by Oscarsson et al. (2002) except that the medium was supplemented with $10 \mathrm{mM}$ EDTA to inhibit $\alpha$-haemolysin activity.

Contact haemolysin assay. The assay was performed according to Sansonetti et al. (1986).

Detection of CNF, CDT and enterohaemorrhagic $E$. coli

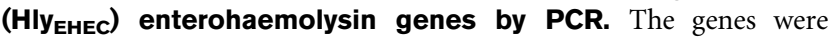
identified as described by Blanco et al. (1996), Wieler et al. (2000) and Osek \& Weiner (2003)
Cell-detaching (CD) assay. CD activity of exponential and stationary culture filtrates and bacterial cell suspensions, as well as bacteria heated at $56^{\circ} \mathrm{C}$ for $10 \mathrm{~min}$ and UV-irradiated for $10 \mathrm{~min}$, was screened on Int 407 (human jejunum carcinoma) and Caco-2 (human colon carcinoma) cell lines according to Elliott et al. (1998). A semiconfluent monolayer of Int 407 or Caco-2 cells in a 96-well tissue culture plate was washed three times with PBS-CM and then $100 \mu \mathrm{l}$ aliquots of bacterial culture filtrates or bacterial cell suspensions of exponential or stationary growth phase diluted 1:100 with PBS-CM were added to duplicate wells and the plate was incubated at $37^{\circ} \mathrm{C}$ for $90 \mathrm{~min}$ under $5 \% \mathrm{CO}_{2}$. Monolayers were washed three times with PBS-CM, fixed with $70 \%$ methanol for $10 \mathrm{~min}$, stained with $0 \cdot 13 \%$ crystal violet for $10 \mathrm{~min}$ and then briefly destained in sterile water. Cell detachment was quantified by eluting crystal violet with a solution of $50 \%$ ethanol, $49 \%$ water and $1 \%$ SDS, and measuring absorbance of the eluate at $590 \mathrm{~nm}$. CD activity was expressed as the mean percentage of cell detached from a monolayer in five independent assays in comparison with intact cell monolayers and $E$. coli strains used as negative controls.

Data analysis. Regression analysis was used to evaluate the relationship between the mean haemolytic activity of bacterial cell suspensions and the mean cell-detaching activity of bacterial cells of the E. coli strains examined.

\section{RESULTS AND DISCUSSION}

Among 27 E. coli isolates examined, two strains $(7 \cdot 4 \%)$ showed the presence of genes for CDT 1 and $14(51 \cdot 8 \%)$ showed the genes encoding CNF1. None of the isolates

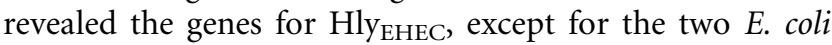
O26 strains used as controls. All of the E. coli isolates were haemolytic within $4 \mathrm{~h}$ of incubation on all blood agar media used except the media containing $10 \mathrm{mM}$ EDTA, indicating that the haemolysin produced was calcium-dependent (Table 1). After $4 \mathrm{~h}$ of incubation, $25(92 \cdot 6 \%)$ of the culture filtrates and all 27 bacterial cell suspensions showed comparable haemolytic activity with mean levels of $35 \cdot 8$ and $37.9 \%$, respectively. Both the cell-free (HlyA) and the cell-bound haemolysins were calcium-dependent and their activity was inhibited in the presence of dextran 4 and dextran 8 but not in the presence of sucrose or cholesterol. UV irradiation inhibited haemolytic activity of $10(37 \%)$ culture filtrates and all bacterial cell suspensions; this loss of activity was associated with killing of bacteria as determined by the lack of growth on MacConkey agar plates. Heating at $56{ }^{\circ} \mathrm{C}$ for $10 \mathrm{~min}$ inhibited HlyA present in $20(74 \cdot 1 \%)$ filtrates and haemolytic activity of all 27 bacterial cell suspensions, although it had no influence on growth of the bacteria on MacConkey agar plates. In contrast, after $24 \mathrm{~h}$ of incubation, haemolytic activity was detected in three $(11 \cdot 1 \%)$ culture filtrates and it was associated with 25 $(92 \cdot 6 \%)$ bacterial cell suspensions.

No haemolytic activity was observed in the filtrates obtained from bacteria suspended in PBS-CM and incubated at $37^{\circ} \mathrm{C}$ for 90 min without RBCs, indicating that cell-free haemolysin was not released under these conditions. The incubation period influenced neither the haemolytic activity of the bacterial cells nor the cell-free haemolysin. None of the E. coli isolates produced contact haemolysins as tested by the contact haemolysin assay. For promoting contact 
Table 1. Characters of analysed E. coli strains

HAA represents haemolytic activity on agar plates supplemented with whole sheep blood unless indicated.

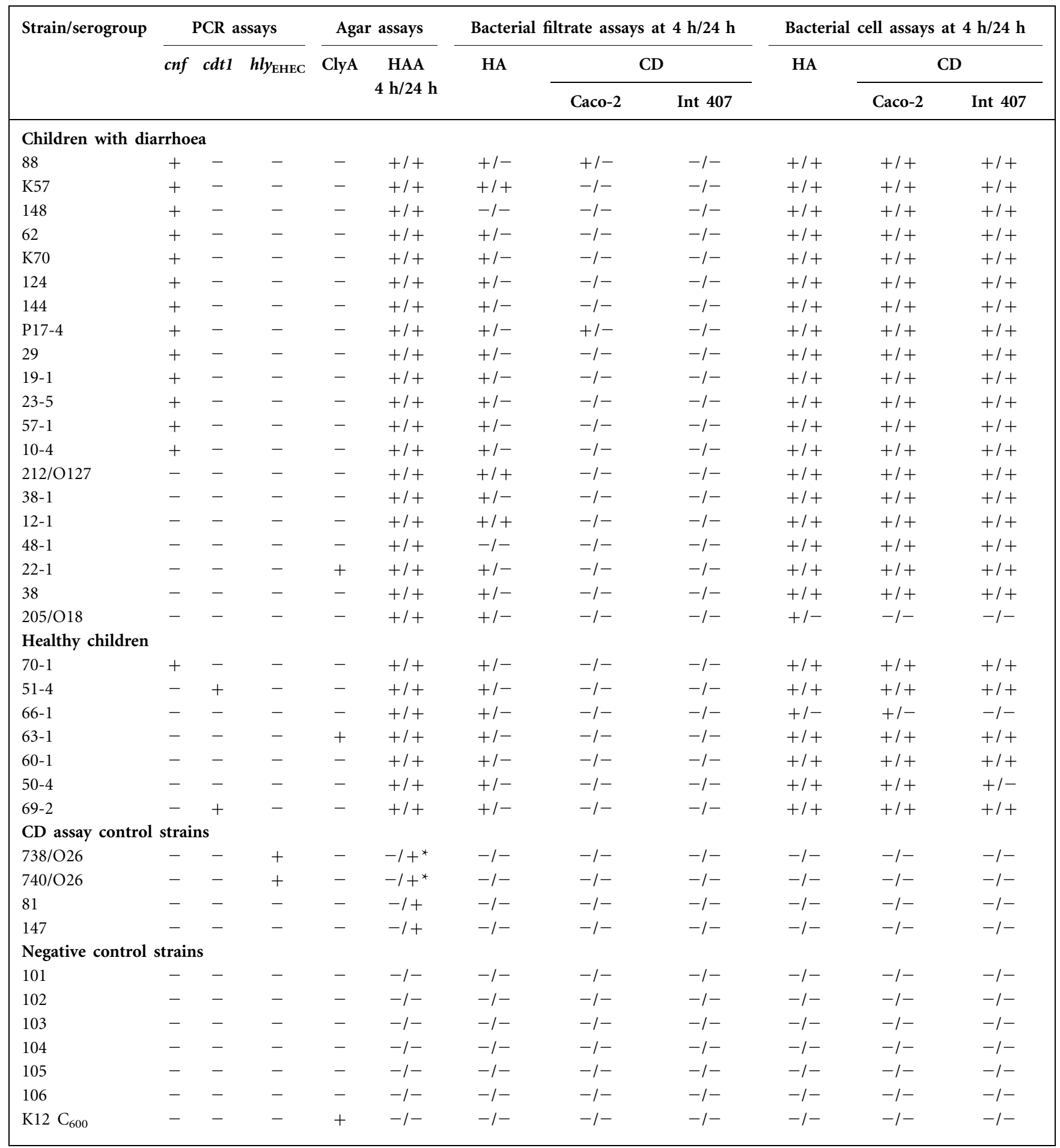

${ }^{\star}$ Haemolytic activity on agar plates supplemented with washed sheep erythrocytes.

haemolysin production, close contact between bacteria and RBCs (as is achieved by centrifugation) is important. No contact haemolysin activity is detected when bacterial suspensions are simply mixed with sheep erythrocytes and incubated. Cell-bound contact calcium-dependent haemolysin was described by Haque et al. (1994) among EAEC. According to their study, this haemolysin was produced by aggregative E. coli isolates cultured only in Casamino 

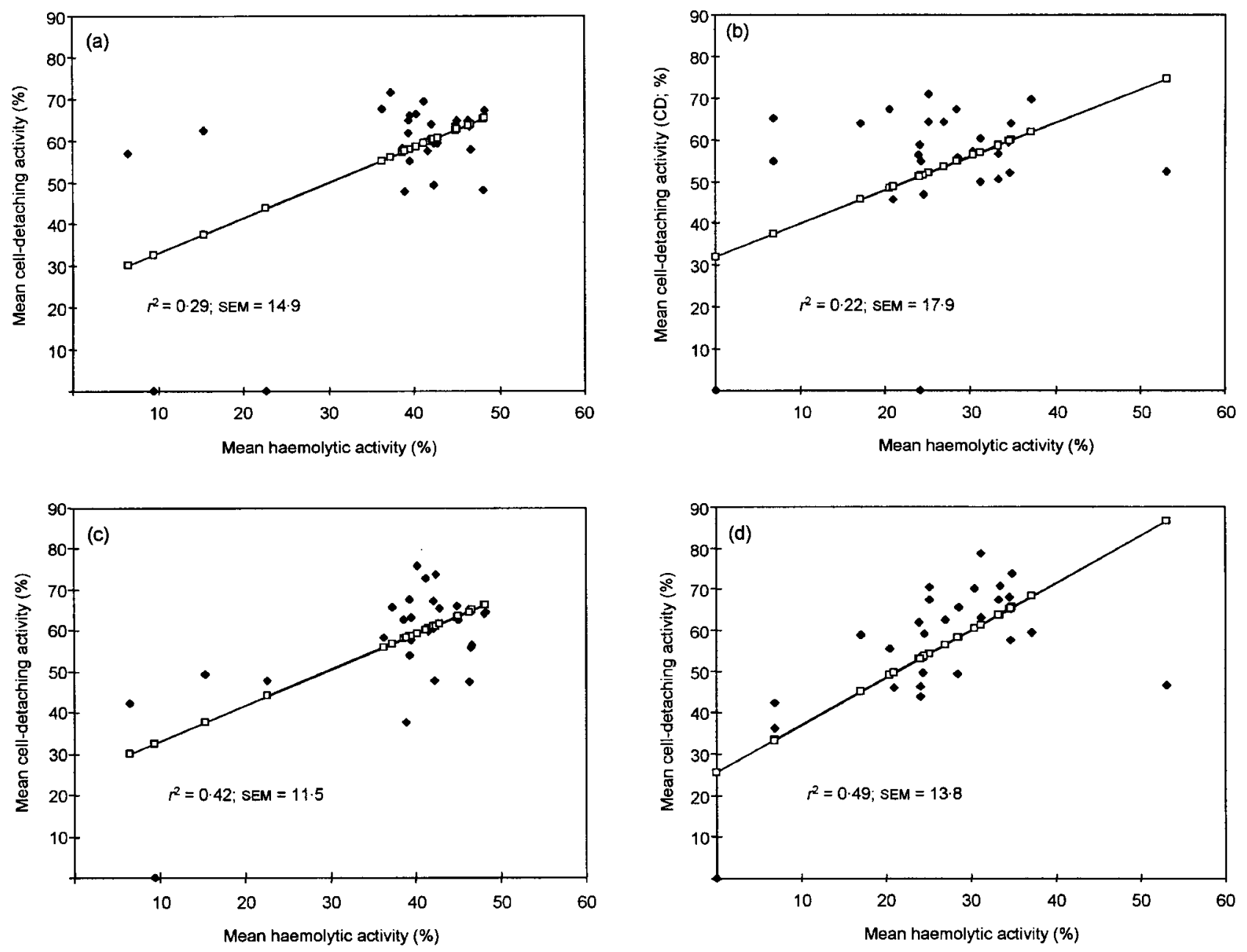

Fig. 1. Scatter plots of relationships between the mean haemolytic and cell-detaching activities of bacterial cells of $27 \mathrm{E}$. coli isolates examined on Int 407 (a, b) and Caco-2 (c, d) cell lines after 4 h (exponential phase; a, c) and 24 h (stationary phase; b, d). Open squares show the predicted CD activity, whereas filled diamonds show the measured values. Mean \pm SEM CD activities in each panel are: $61 \cdot 0 \pm 9 \cdot 4 \%$ (a), $58 \cdot 5 \pm 11 \cdot 6 \%$ (b), $59 \cdot 4 \pm 10 \cdot 3 \%$ (c) and $58 \cdot 7 \pm 9 \cdot 6 \%$ (d). Mean \pm SEM haemolytic activities in each panel are: $37 \cdot 9 \pm 1 \cdot 9 \%$ (a), $25 \cdot 2 \pm 2 \cdot 2 \%$ (b), $37 \cdot 9 \pm 1 \cdot 9 \%$ (c) and $25 \cdot 2 \pm 13 \cdot 8 \%(d)$.

acids/yeast extract broth supplemented with $1 \mathrm{mM} \mathrm{CaCl}{ }_{2}$ and demonstration of the activity required close contact between bacteria and RBCs. In contrast, the cell-bound haemolysin detected among E. coli isolates examined in the present study was produced by bacteria cultured in various liquid media, e.g. Luria-Bertani broth, tryptose soy broth or yeast extract medium (data not shown). Furthermore, haemolytic activity of the cell-bound haemolysin was detected in bacterial suspensions only mixed with erythrocytes and incubated at $37^{\circ} \mathrm{C}$. Another contact haemolysin demonstrated by Sansonetti et al. (1986) among EIEC, although calcium-independent, also required the close contact between bacteria and RBCs achieved by centrifugation. ClyA cytolysin that is calcium-independent and inhibited by cholesterol was released upon contact with mitomycin C by two $(7 \cdot 4 \%)$ of the 27 haemolytic E. coli tested as well as by the E. coli K12 strain.
In the cell-detaching assay only $2(8 \%)$ of the 25 exponential culture filtrates containing HlyA had cell-detaching activity for Caco-2 cells and none affected Int 407 cells. In contrast, cell-detaching activity was mostly associated with the bacterial cells (Table 1). A scatter plot to show the relationship between the haemolytic activity of bacterial cells and the cell-detaching activity of $E$. coli isolates was constructed and analysed by the regression method. This analysis indicates a close relationship between the haemolytic and the Caco-2 cell-detaching activities of E. coli cells as shown in Fig. 1. None of the control E. coli strains showed cell-detaching activity.

In the present study, most haemolytic E. coli showed HlyA production, and all the isolates demonstrated cell-bound haemolytic activity during the exponential growth phase. However, according to the RAPD (random amplified 
polymorphic DNA) assay, all the haemolytic E. coli strains exhibited distinct patterns, indicating the presence of different genetic groups (data not shown). The mean haemolytic activity of the filtrates was comparable to that of the bacterial cell suspensions. HlyA present in the culture filtrates was stable and active during the incubation period and the bacterial cells did not release any cell-free haemolysin during the same time of incubation. The cell-bound haemolysin was similar to HlyA with regard to calcium-dependency and lack of the activity in the presence of dextran 4 and dextran 8 , but not in the presence of sucrose or cholesterol. In contrast to cell-free HlyA, the cell-bound haemolysin was detected in E. coli cultures incubated for $24 \mathrm{~h}$. Moreover, inactivation of the cell-bound haemolytic activity by heating or UV irradiation of the E. coli cells tested was associated with loss of cell-detaching ability. The influence of other

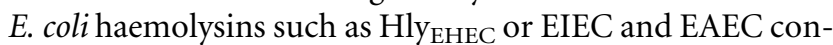
tact haemolysins on cell-detaching activity was excluded. Similarly, there was no association of cytolysin ClyA with haemolytic or cell-detaching activity of the isolates examined. The six non-haemolytic E. coli strains used in the $\mathrm{CD}$ assay as negative controls were found to be noncytotoxic for the cultured cells. The two enterohaemolysinproducing E. coli $\mathrm{O} 26$ and the isolates that were haemolytic on blood agar plates after $24 \mathrm{~h}$ of incubation had no ability to detach cells in vitro, in agreement with Marques et al. (1995).

Smith (1963) differentiated two main E. coli haemolysins, cell-free haemolysin $\alpha$ and cell-associated haemolysin $\beta$. The cell-bound haemolysin $\beta$ was very similar to haemolysin $\alpha$, but it was not neutralized by antiserum to haemolysin $\alpha$ and its activity was associated only with intact bacterial cells (Short \& Kurtz, 1971). Gadeberg et al. (1983) showed that washed intact haemolytic E. coli cells and the supernatants of the same E. coli cultures containing HlyA were cytotoxic for leukocytes. In our study the cell-detaching effect was associated with viable bacteria but not with culture filtrates containing HlyA. The E. coli strains examined in the present study were isolated from stool specimens, so it is possible that epithelial intestinal cells are more sensitive to cellbound haemolysin than to HlyA. As the contact haemolysin of EIEC is considered to contribute to their virulence, it seems possible that the cell-bound haemolysin of E. coli strains isolated from stool specimens of patients with diarrhoea in our study may be associated with pathogenicity. On the other hand, the cell-bound haemolysin-producing E. coli isolates were recovered from healthy children as well as from those with diarrhoea. This suggests that the haemolysin is not associated with pathogenicity of these strains or it may be a virulence factor but only under particular in vivo conditions. The association of the cell-bound haemolysin with virulence of $E$. coli strains remains to be determined.

The results obtained in the present study provide evidence that haemolysin $\beta$ or an unknown cell-bound haemolysin rather than cell-free HlyA was associated with in vitro celldetaching activity of $E$. coli isolates examined.

\section{REFERENCES}

Beutin, L., Montenegro, M. A., Ørskov, I., Ørskov, F., Prada, J., Zimmermann, S. \& Stephan, R. (1989). Close association of verotoxin (Shiga-like toxin) production with enterohemolysin production in strains of Escherichia coli. J Clin Microbiol 27, 2559-2564.

Bhakdi, S., Mackman, N., Nicaud, J. M. \& Holland, I. B. (1986). Escherichia coli hemolysin may damage target cell membranes by generating transmembrane pores. Infect Immun 52, 63-69.

Blanco, M., Blanco, J. E., Blanco, J., Alonso, M. P., Balsalobre, C., Mourino, M., Madrid, C. \& Juarez, A. (1996). Polymerase chain reaction for detection of Escherichia coli strains producing cytotoxic necrotizing factor type 1 and type 2 (CNF1 and CNF2). J Microbiol Methods 26, 95-101.

Bohach, G. A. \& Snyder, I. S. (1985). Chemical and immunological analysis of the complex structure of Escherichia coli $\alpha$-hemolysin. J Bacteriol 164, 1071-1080.

Elliott, S. J., Srinivas, S., Albert, M. J., Alam, K., Robins-Browne, R. M., Gunzburg, S. T., Mee, B. J. \& Chang, B. J. (1998). Characterization of the roles of hemolysin and other toxins in enteropathy caused by alpha-hemolytic Escherichia coli linked to human diarrhea. Infect Immun 66, 2040-2051.

Fábrega, V. L. A., Ferreira, A. J. P., Reis da Silva Patrício, F., Brinkley, C. \& Scaletsky, I. C. A. (2002). Cell-detaching Escherichia coli (CDEC) strains from children with diarrhea: identification of a protein with toxigenic activity. FEMS Microbiol Lett 217, 191-197.

Figueirědo, P. M., Catani, C. F. \& Yano, T. (2003). Serum highdensity lipoprotein (HDL) inhibits in vitro enterohemolysin (EHly) activity produced by enteropathogenic Escherichia coli. FEMS Immunol Med Microbiol 38, 53-57.

Gadeberg, O. V., Ørskov, I. \& Rhodes, J. M. (1983). Cytotoxic effect of an alpha-hemolytic Escherichia coli strain on human blood monocytes and granulocytes in vitro. Infect Immun 41, 358-364.

Gomes, T. A., Abe, C. M. \& Marques, L. R. (1995). Detection of HeLa cell-detaching activity and alpha-hemolysin production in enteroaggregative Escherichia coli strains isolated from feces of Brazilian children. J Clin Microbiol 33, 3364.

Gunzburg, S. T., Chang, B. J., Elliott, S. J., Burke, V. \& Gracey, M. (1993). Diffuse and enteroaggregative patterns of adherence of enteric Escherichia coli isolated from aboriginal children from the Kimberley region of Western Australia. J Infect Dis 167, 755-758.

Haque, M. A., Ohki, K., Kikuchi, M. \& Kohashi, O. (1994). Contact hemolysin production by strains of enteroaggregative Escherichia coli isolated from children with diarrhea. J Clin Microbiol 32, 1109-1111.

Jorgensen, S. E., Short, E. C., Jr, Kurtz, H. J., Mussen, H. K. \& Wu, G. K. (1976). Studies on the origin of the $\alpha$-haemolysin produced by Escherichia coli. J Med Microbiol 9, 173-189.

Marques, L. R., Abe, C. M., Griffin, P. M. \& Gomes, T. A. (1995). Association between alpha-hemolysin production and HeLa celldetaching activity in fecal isolates of Escherichia coli. J Clin Microbiol 33, 2707-2709.

Okeke, I. N., Steinrück, H., Kanack, K. J., Elliott, S. J., Sundström, L., Kaper, J. B. \& Lamikanra, A. (2002). Antibiotic-resistant celldetaching Escherichia coli strains from Nigerian children. J Clin Microbiol 40, 301-305.

Oscarsson, J., Westermark, M., Beutin, L. \& Uhlin, B. E. (2002). The bacteriophage-associated Ehly1 and Ehly2 determinants from Escherichia coli $\mathrm{O} 26: \mathrm{H}^{-}$strains do not encode enterohemolysins per se but cause release of the ClyA cytolysin. Int J Med Microbiol 291, 625-631. 
Osek, J. \& Weiner, M. (2003). Prevalence of $c d t$-III gene encoding cytolethal distending toxin (CDT) among Escherichia coli strains isolated from pig with diarrhea. Bull Vet Inst Pulawy 47, $17-22$.

Sansonetti, P. J., Ryter, A., Clerc, P., Maurelli, A. T. \& Mounier, J. (1986). Multiplication of Shigella flexneri within HeLa cells: lysis of the phagocytic vacuole and plasmid-mediated contact hemolysis. Infect Immun 51, 461-469.

Short, E. C., Jr \& Kurtz, A. J. (1971). Properties of the hemolytic activities of Escherichia coli. Infect Immun 3, 678-687.
Smith, H. W. (1963). The haemolysins of Escherichia coli. J Pathol Bacteriol 85, 197-211.

Taneike, J., Zhang, H.-M., Wakisaka-Saito, N. \& Yamamoto, T. (2002). Enterohemolysin operon of Shiga toxin-producing Escherichia coli: a virulence function of inflammatory cytokine production from human monocytes. FEBS Lett 524, 219-224.

Wieler, L. H., Busse, B., Steinrück, H., Beutin, L., Weber, A., Karch, H. \& Baljer, G. (2000). Enterohemorrhagic Escherichia coli (EHEC) strains of serogroup O118 display three distinctive clonal groups of EHEC pathogens. J Clin Microbiol 38, 2162-2169. 